\title{
ДЕСТРУКТИВНАЯ АКТИВНОСТЬ И ПРОДУКЦИЯ ВНЕКЛЕТОЧНЫХ ПЕРОКСИДАЗ У МИКРОМИЦЕТОВ С РАЗЛИЧНОЙ ЭКОЛОГИЧЕСКОЙ СТРАТЕГИЕЙ
}

\author{
О.В. ТУРКОВСКАЯ, Е.В. ДУБРОВСКАЯ, В.С. ГРИНЕВ, С.А. БАЛАНДИНА, \\ Н.Н. ПОЗДНЯКОВА
}

Загрязнение окружающей среды природными и техногенными поллютантами остается серьезной проблемой. На сельскохозяйственные угодья попадают такие масштабные и опасные поллютанты, как нефть и полициклические ароматические углеводороды (ПАУ). Природные экосистемы имеют мощный детоксикационный потенциал, который обеспечивается деструктивной активностью микроорганизмов, в том числе аскомицетов - одной из самых многочисленных групा царства грибов. В настоящей работе мы впервые показали способность ряда ранее не изученных штаммов аскомицетов различной родовой принадлежности активно разрушать нефть и ПАУ, продуцируя внеклеточные пероксидазы. Нашей целью было изучение деградации нефти и полициклических ароматических углеводородов микромицетами с различной экологической стратегией, а также выявление лигнинолитических ферментов, участвующих в окислении этих поллютантов. Использовали четыре штамма аскомицетов - Fusarium oxysporum IBPPM543, Lecanicillium aphanocladii IBPPM542, Cladosporium herbarum MUT3238 и Geotrichum candidum MUT4803, имеющих различную таксономическую принадлежность и экологическую стратегию. Грибы культивировали в жидких средах различного состава с добавлением исследуемых полютантов нефти, ПАУ, красителей антрахинонового типа. Через 14 сут с помощью газожидкостной хроматографии определяли убыль поллютантов и содержание основных продуктов их деградации. Активность лигнинолитических ферментов оценивали спектрофотометрически по скорости окисления соответствующих тестовых субстратов. У всех исследованных грибов выявлена нефтеокисляющая активность: утилизация нефти проходила на 46-82 \% от исходной концентрации 5 г/л за 14 сут. C. herbarum MUT 3238 окислял все исследованные ПАУ (антрацен, фенантрен и флуорен) практически полностью (исходная концентрация 0,05 г/л). L. aphanocladii IBPPM 542 деградировал антрацен, фенантрен и флуорен соответственно на 40, 63 и $81 \%$, F. oxysporum IВРPМ 543 окислял фенантрен и флуорен лишь на 20 и $40 \%$, G. candidum MUT4803 разрушал ПАУ не более чем на $18 \%$. Антрацен окислению не подвергался. Деградация поллютантов сопровождалась продукцией внеклеточных пероксидаз у всех грибов, за исключением G. candidum. Их активность в значительной степени стимулировалась ионами $\mathrm{Mn}^{2+}$. Следует отметить, что у C. herbarum и L. aphanocladii эти ферменты обнаружены нами впервые. Активность лигнинпероксидаз и лакказ у исследованных грибов мы не обнаружили. Полученные результаты указывают на то, что представители двух широко распространенных в природе видов аскомицетов C. herbarum $\boldsymbol{u}$ F. oxysporum, а также штамм менее известного и мало изученного вида L. aphanocladii обладают деструктивным потенциалом в отношении нефти и ПАУ, что предполагает их участие в процессах самоочищения природы от этих поллютантов. Выявление лигнинолитических Mnпероксидаз и соответствующих продуктов деградации ПАУ свидетельствует в пользу экологически целесообразного пути утилизации ПАУ, что снижает негативные последствия, связанные с возможным образованием токсичных метаболитов. У штамма G. candidum окисление нефти и ПАУ, вероятно, обусловлено активностью других ферментов, например цитохром Р450-монооксигеназы. Кроме того, велика вероятность наличия у этого штамма так называемой обесцвечивающей пероксидазы (dye-peroxidase), имеющей узкий субстратный спектр и катализирующей деградацию антрахиноновых красителей.

Ключевые слова: аскомицеты, Fusarium oxysporum, Lecanicillium aphanocladii, Cladosporium herbarum, биодеградация, полициклические ароматические углеводороды, нефть, лигнинолитические ферменты, пероксидазы.

Загрязнение окружающей среды природными и техногенными поллютантами остается серьезной проблемой. На сельскохозяйственные угодья попадают такие масштабные и опасные поллютанты, как нефть и полициклические ароматические углеводороды (ПАУ): нефть - из-за находящихся вблизи нефтедобывающих или нефтеперерабатывающих предприятий (1), ПАУ - в результате природных пожаров и человеческой дея-

* Исследование выполнено при поддержке грантов РНФ № 16-14-00081 (в части деградации ПАУ) и РФФИ № 18-29-05062 (в части деградации нефти). 
тельности, связанной с использованием горючего органического сырья (2). Это создает угрозу накопления токсичных веществ в кормовых и пищевых растениях. Природные экосистемы имеют мощный детоксикационный потенциал, который обеспечивается деструктивной активностью микроорганизмов, в том числе аскомицетов - одной из самых многочисленных групп царства грибов.

Виды рода Fusarium характеризуются высокой метаболической активностью и адаптационной пластичностью (3). В первую очередь они известны как наносящие вред сельскому хозяйству, вызывающие заболевания и токсикозы у растений и животных. Вид Fusarium oxysporum часто служит моделью для исследований взаимодействия растения с патогеном (4). Однако преобладающее число его представителей ведет сапротрофный образ жизни в почве, используя в качестве источников питания сложные углеводы и лигноцеллюлозу. Известны штаммы, образующие взаимовыгодный симбиоз с растениями и даже защищающие их от болезней $(5,6)$. Показано участие Fusarium в процессах деградации поллютантов, в том числе ПАУ и нефти $(7,8)$.

Грибы рода Cladosporium вносят значительный вклад в деградацию растительных остатков, но могут вызвать заболевания растений, порчу сена и зерна в хранилищах, выделяя опасные для животных и человека токсины. О деградации этими грибами поллютантов известно мало: C. resinae описан как креозотный, или керосиновый, гриб, корродирующий насосы; способность метаболизировать антрацен показана у C. herbarum (9), флуорантен - у C. sphaerospermum (10).

Представители родов Geotrichum и Lecanicillium заселяют другие типы биотопов. Geotrichum candidum вызывает различные гнили на органических субстратах, в том числе на плодах, и считается условно-патогенным грибом, возбудителем оппортунистических микозов. В то же время штаммы этого вида используют в производстве элитных сортов сыра и ряда кисломолочных продуктов (11). Данные о деградативных свойствах $G e$ otrichum в основном касаются способности этого гриба обесцвечивать синтетические красители, в том числе содержащие конденсированные ароматические кольца $(12,13)$, трансформировать 2,4,6-тринитротолуол (14) и детергенты (15). Вид Lecanicillium aphanocladii (до 2001 года известный как Verticillium lecanii) описан как энтомопатогенный $(16,17)$ и паразитирующий на других грибах (18). Его деградативные свойства в отношении поллютантов практически не исследованы. Имеются данные о представителях других видов этого рода: L. saksenae - деструкторе пестицидов (19), V. lecanii - деструкторе 2,4-дихлорфенола, 2,4-дихлорфеноксиуксусной кислоты (20) и антрацена (9).

Деструкция природных веществ и ксенобиотиков у грибов осуществляется с помощью вне- и внутриклеточных ферментов. Внеклеточные лигнинолитические ферменты - лакказы и пероксидазы продуцируются многими видами базидио- и аскомицетов в процессе деградации лигноцеллюлозы и часто рассматриваются как ключевые ферменты деградации поллютантов (21). Сообщений о продукции подобных ферментов у L. aphanocladii и C. herbarum мы не обнаружили.

Внутриклеточные ферменты, участвующие в деградации поллютантов, представлены в первую очередь цитохром Р450-зависимыми монооксигеназами (цитохром Р450-монооксигеназами), которые присутствуют в клетках грибов независимо от их способности продуцировать лигнинолитические внеклеточные ферменты. Предполагается, что путь первичного окисления ПАУ тем или иным ферментом зависит от ряда условий, при этом в случае 
катализируемого цитохром Р450-монооксигеназой гидроксилирования ароматического кольца и ряда последующих трансформаций могут образоваться эпоксиды и транс-дигидродиолы, которые являются мощными канцерогенами. В то же время опосредованное пероксидазой или лакказой окисление этих веществ происходит с образованием хинонов, которые далее метаболизируются грибом до соединений, которые менее токсичны, чем исходные ПАУ. Именно поэтому окисление ПАУ лигнинолитическими ферментами может быть более логичной стратегией для детоксикации загрязненной окружающей среды (22).

В этой связи представляет интерес оценить не только деструктивную активность ряда грибов-аскомицетов - постоянных и массовых обитателей фитоценозов, характеризующую их участие в самоочищении природной среды, но и определить наличие у них лигнинолитических ферментов, понижающих экологические риски, связанные с возможным образованием токсичных метаболитов.

В настоящей работе мы впервые показали способность ряда ранее не изученных штаммов аскомицетов различной родовой принадлежности активно разрушать нефть и ПАУ, продуцируя внеклеточные пероксидазы.

Нашей целью было изучение деградации нефти и полициклических ароматических углеводородов микромицетами с различной экологической стратегией, а также выявление лигнинолитических ферментов, участвующих в окислении этих поллютантов.

Методика. Использовали четыре штамма аскомицетов: Fusarium oxysporum IBРРМ543 (выделен из старых шпал, пропитанных креозотом; IВРPМ - Коллекция ризосферных микроорганизмов Института биохимии и физиологии растений и микроорганизмов РАН), Lecanicillum aphanocladii IBPРМ542 (выделен из спорокарпа базидиомицета Lentinus sp.), Cladosporium herbarum MUT3238 и Geotrichum candidum MUT4803 (получены из Микотеки Туринского Университета - Mycotheca Universitatis Taurinensis, г. Турин, Италия).

Грибы культивировали в колбах в богатой среде для базидиомицетов, содержащей $\mathrm{NH}_{4} \mathrm{NO}_{3}-0,724, \mathrm{KH}_{2} \mathrm{PO}_{4}-1,0, \mathrm{MgSO}_{4} \cdot 7 \mathrm{H}_{2} \mathrm{O}-1,0$, $\mathrm{KCl}-0,5$, дрожжевой экстракт $-0,5, \mathrm{FeSO}_{4} \cdot 7 \mathrm{H}_{2} \mathrm{O}-0,01, \mathrm{ZnSO}_{4} \cdot 7 \mathrm{H}_{2} \mathrm{O}-$ $0,0028, \mathrm{CaCl}_{2} \cdot 2 \mathrm{H}_{2} \mathrm{O}-0,033$, глюкоза $-10,0$, пептон $-10,0$ г/л, $\mathrm{pH} 6,0$ (23). Из-за оптической непрозрачности этой среды для наблюдения за обесцвечиванием красителей использовали среду Кирка (24) в нашей модификации: $\mathrm{KH}_{2} \mathrm{PO}_{4}-2,0, \mathrm{MgSO}_{4}-0,348, \mathrm{CaCl}_{2} \cdot 2 \mathrm{H}_{2} \mathrm{O}-0,143, \mathrm{NH}_{4} \mathrm{NO}_{3}-$ 1,02 г/л; раствор микроэлементов - 10, тиамин - 0,5 мл/л. Раствор микроэлементов включал нитрилтриацетат $-1,5, \mathrm{MgSO}_{4} \cdot 7 \mathrm{H}_{2} \mathrm{O}-3,0$, $\mathrm{MnSO}_{4} \cdot \mathrm{H}_{2} \mathrm{O}-0,5, \mathrm{NaCl}-1,0, \mathrm{FeSO}_{4} \cdot 7 \mathrm{H}_{2} \mathrm{O}-0,1, \mathrm{CoSO}_{4}-0,1, \mathrm{CaCl}_{2}-$ $0,082, \mathrm{ZnSO}_{4}-0,1, \mathrm{CuSO}_{4} \cdot 5 \mathrm{H}_{2} \mathrm{O}-0,01, \mathrm{AlK}\left(\mathrm{SO}_{4}\right)_{2}-0,01, \mathrm{H}_{3} \mathrm{BO}_{4}-$ 0,01, $\mathrm{NaMoO}_{4}-0,01$ г/л; рН 6,0 поддерживали 25 мМ фосфатным буфером. Источником углерода и энергии служила мальтоза в конечной концентрации $1 \%$.

Деградативную активность грибов оценивали по отношению к ПАУ (антрацен, фенантрен и флуорен), синтетическим красителям антрахинонового типа (Acid Blue 62 и Reactive Blue 4) и сырой нефти (содержание алканов - 47,4, нафтенов - 22,3, низкомолекулярных ароматических веществ - 4,4, высокомолекулярных ароматических веществ - 5,4, смол 3,9 , асфальтенов - 16,6 \%). ПАУ и нефть вносили в среду культивирования в виде раствора в хлороформе, антрахиноновые красители - в виде водного раствора. Конечная концентрация для ПАУ и антрахиноновых красителей составляла 0,05 г/л, для нефти - 5,0 г/л. Среды засевали 2-су- 
точным инокулятом грибов и культивировали при температуре $26{ }^{\circ} \mathrm{C}$ и аэрации 120 об/мин, через 2 сут в колбы вносили поллютанты, в контрольные варианты - 100 мкл растворителя. Через 14 сут оценивали убыль поллютантов, содержание основных продуктов метаболизма и активность лигнинолитических ферментов.

ПАУ и продукты их деградации экстрагировали из культуральной жидкости хлороформом (трижды по 5 мл), экстракты объединяли, упаривали досуха и анализировали методом газожидкостной хроматографии (ГЖХ) на хроматографе GC-2010 («Shimadzu Deutschland GmbH», Германия) с пламенно-фотометрическим детектором. Вещества разделяли на колонке HP5 («Agilent Technologies Inc.», США), газ-носитель - гелий. Температуру колонки $200{ }^{\circ} \mathrm{C}$ поддерживали 3 мин, затем увеличивали до $270{ }^{\circ} \mathrm{C}$ со скоростью $15{ }^{\circ} \mathrm{C} /$ мин, и эту температуру поддерживали еще 2 мин. Перед проведением ГЖХ 2-карбоксибензальдегид, 2,2'-дифеновую и фталевую кислоты метилировали $\mathrm{CH}_{3} \mathrm{COCl}$. Антрацен (время удерживания 4,15 мин), 9,10-антрахинон (5,39 мин), фенантрен (4,08 мин), фенантрен-9,10-хинон (6,86 мин), флуорен (5,57 мин), 9-флуоренон (4,33 мин), 2карбоксибензальдегид (7,31 мин), 2,2' -дифеновую кислоту (6,7 мин), фталевую кислоту $(8,99$ мин) использовали как маркерные соединения для идентификации ПАУ и продуктов их окисления.

Убыль красителей тестировали спектрофотометрически, отбирая из колб аликвоты (2 мл) через определенные промежутки времени с последующим измерением поглощения при $\lambda=590$ нм (25). Остаточную нефть из среды культивирования экстрагировали хлороформом (трижды по 5 мл), экстракты объединяли и упаривали досуха. Общее содержание нефти в образцах определяли адсорбционной хроматографией с гравиметрическим окончанием (26).

Активность ферментов оценивали спектофотометрически (Evolution 60, «Thermo Scientific», США): лакказу - по скорости окисления диаммониевой соли 2,2'-азино-бис(3-этилбензотиазолин-6-сульфоновой кислоты) (ABTS) при $\lambda=436$ нм (27); Мn-пероксидазу - по скорости окисления 2,6-диметоксифенола в присутствии $\mathrm{H}_{2} \mathrm{O}_{2}$ и $\mathrm{Mn}^{2+}$ при $\lambda=468$ нм (28); лигнин-пероксидазу - по образованию продукта окисления вератрилового спирта при $\lambda=310$ нм (29). Пероксидазную активность рассчитывали как разницу между скоростью окисления субстратов в присутствии и без $\mathrm{H}_{2} \mathrm{O}_{2}$. За единицу активности (Ед/мл) принимали количество фермента, которое катализировало превращение 1 мкмоль субстрата в минуту.

Повторность во всех вариантах в экспериментах и анализах не менее чем 3-кратная, каждый эксперимент повторяли не менее 3 раз. Статистическую обработку полученных результатов осуществляли в программе Microsoft Excel 2003. На рисунках представлены средние значения $(M)$ и стандартные отклонения $( \pm \mathrm{SD})$.

Результаты. Исследованные грибы обладали нефтеокисляющей активностью. Во всех вариантах происходил интенсивный прирост биомассы, мицелий нарастал в виде пеллет разной величины, через 14 сут нефть была полностью эмульгирована. C. herbarum MUT 3238 и $F$. oxysporum IBPPM 543 разрушали нефть на 82, L. aphanocladii IBPPM 542 на 60, G. candidum MUT4803 - на 46 \%. В литературе представлено довольно много данных об участии микромицетов в деградации нефти (3033), однако отсутствуют публикации, в которых сообщалось бы о нефтеокисляющих свойствах L. aphanocladii.

В отношении ПАУ активность грибов различалась более выраженно. Для $C$. herbarum убыль исходного количества антрацена, фенан- 
трена и флуорена из среды культивирования за 14 сут была практически полной. L. aphanocladii деградировал антрацен, фенантрен и флуорен coответственно на 40, 63 и $81 \%$. F. oxysporum окислял фенантрен и флуорен лишь на 20 и $40 \%$, G. candidum разрушал эти ПАУ не более чем на $18 \%$. Антрацен не подвергался деградации двумя последними грибами (рис. 1).

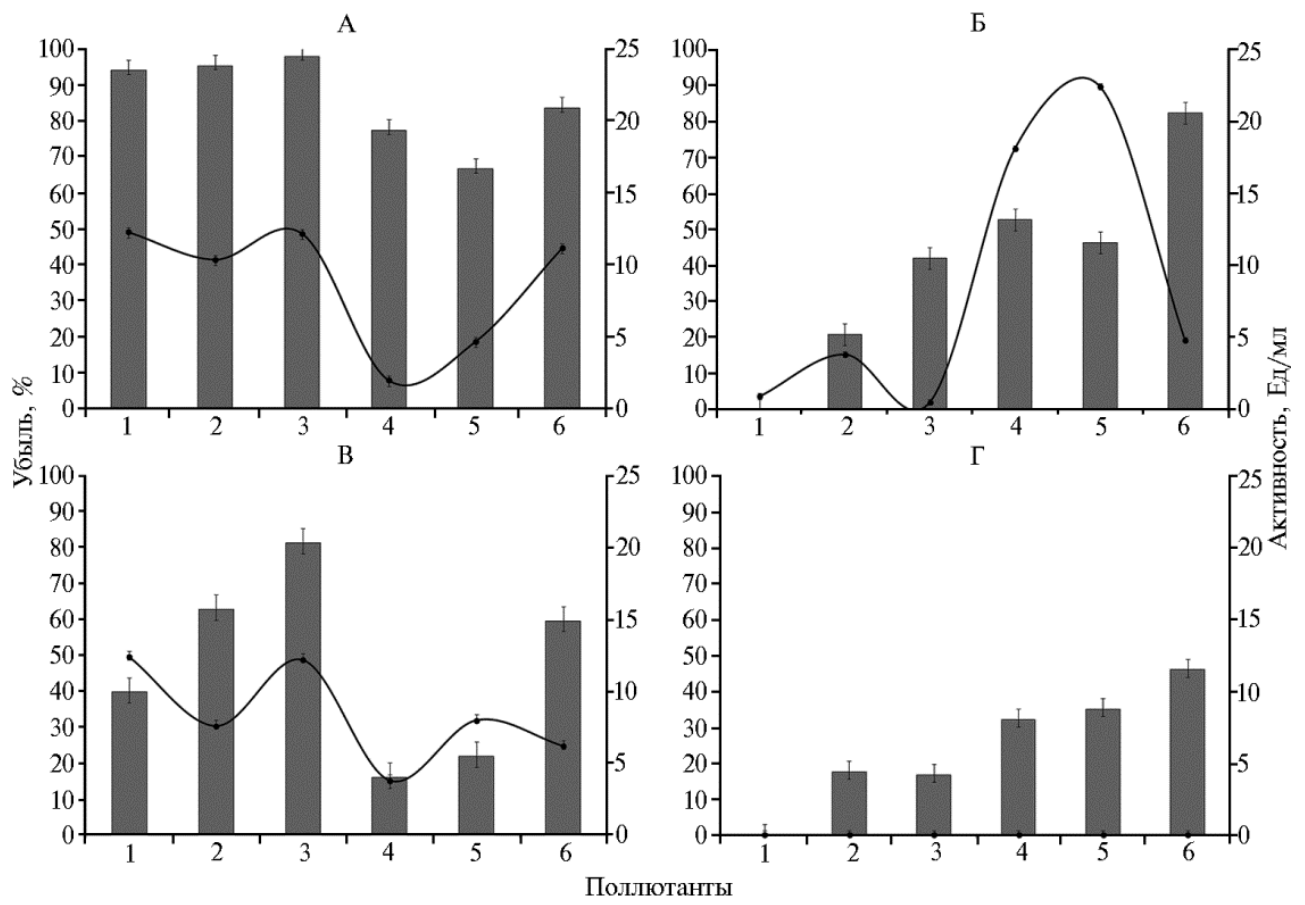

Рис. 1. Деструктивная активность грибов Cladosporium herbarum MUT 3238 (A), Fusarium oxysporum IBPPM 543 (Б), Lecanicillium aphanocladii IBPPM 542 (В), Geotrichum candidum MUT4803 (Г) (гистограмма) в отношении антрацена (1), фенантрена (2), флуорена (3), Reactive Blue 4 (4), Acid Blue 62 (5), нефти (6) и продукция внеклеточных пероксидаз (график) (14-е сут; $n=3$, указаны стандартные отклонения).

Ключевую роль в грибной деградации различных поллютантов приписывают внеклеточным окислительным ферментам, в первую очередь лигнинолитическим (21). В этой связи мы протестировали исследуемые штаммы на активность лакказы, лигнин- и Mn-пероксидазы. Для первичного скрининга грибов на продукцию этих ферментов часто используют их способность обесцвечивать антрахиноновые красители. Как показали тесты, все четыре аскомицета обладали этой способностью, что служило косвенным подтверждением наличия у них подобных ферментов. Однако в условиях нашего эксперимента активность лигнин-пероксидаз и лакказ у грибов мы не выявили. У трех штаммов (за исключением G. candidum) присутствие поллютантов сопровождалось продукцией внеклеточных пероксидаз (см. рис. 1), которые в контрольных вариантах (без поллютанта) отсутствовали. Обнаружено, что их активность в значительной степени (до $40 \%$ ) стимулировалась ионами $\mathrm{Mn}^{2+}$, что делает эти ферменты подобными Мn-зависимым пероксидазам базидиомицетов (34).

По данным литературы, лигнинолитическими ферментами обладают многие микромицеты. Представители рода Fusarium продуцируют Mnзависимую пероксидазу, лигнин-пероксидазу и лакказу, участвующие в реакциях стресса и деградации лигноцеллюлозы (35). Подтверждена роль лакказ в патогенезе грибов (36). Участие ферментов Fusarium в деградации ПАУ описано в различных вариантах. Например, в деградации антрацена 
и бенз(а)антрацена в загрязненных ПАУ мангровых осадках участвует лакказа $F$. solani, в то время как лигнин- и $\mathrm{Mn-пероксидазу} \mathrm{не} \mathrm{детектировали}$ (37). При использовании $F$. oxysporum для трансформации ароматических компонентов в сухих отходах оливковой мельницы обнаружена активность Mn-пероксидазы и Mn-независимой пероксидазы, а действие лакказы не выявлялось (38). У представителей вида G. candidum обнаружены три типа пероксидаз, участие которых в процессах деградации широко обсуждается. Это лигнин- и Мn-пероксидазы (39, 40), а также обесцвечивающая (dyeperoxidase) пероксидаза, которая, как предполагают, имеет узкий субстратный спектр и служит ключевым ферментом в деградации красителей, в том числе содержащих конденсированные ароматические кольца $(12,13)$. В нашем случае выявленная способность штамма G. candidum обесцвечивать антрахиноновые красители при очень низкой окислительной активности в отношении ПАУ позволяет предположить наличие у него именно внеклеточной обесцвечивающей (dye)-пероксидазы. В публикациях других авторов мы не обнаружили сведений о продукции лигнинолитических ферментов L. aphanocladii и C. herbarum.

Безусловно, в процессах жизнедеятельности грибов, в том числе в деградации поллютантов, участвуют и другие ферментные системы, в первую очередь оксигеназы, которые, как известно, являются внутриклеточными ферментами, и их участие связно с предварительным транспортом вещества в клетку. ПАУ обладают низкой растворимостью, что, вероятно, и определило слабую деградацию фенантрена и флуорена (18 \%) у G. candidum.

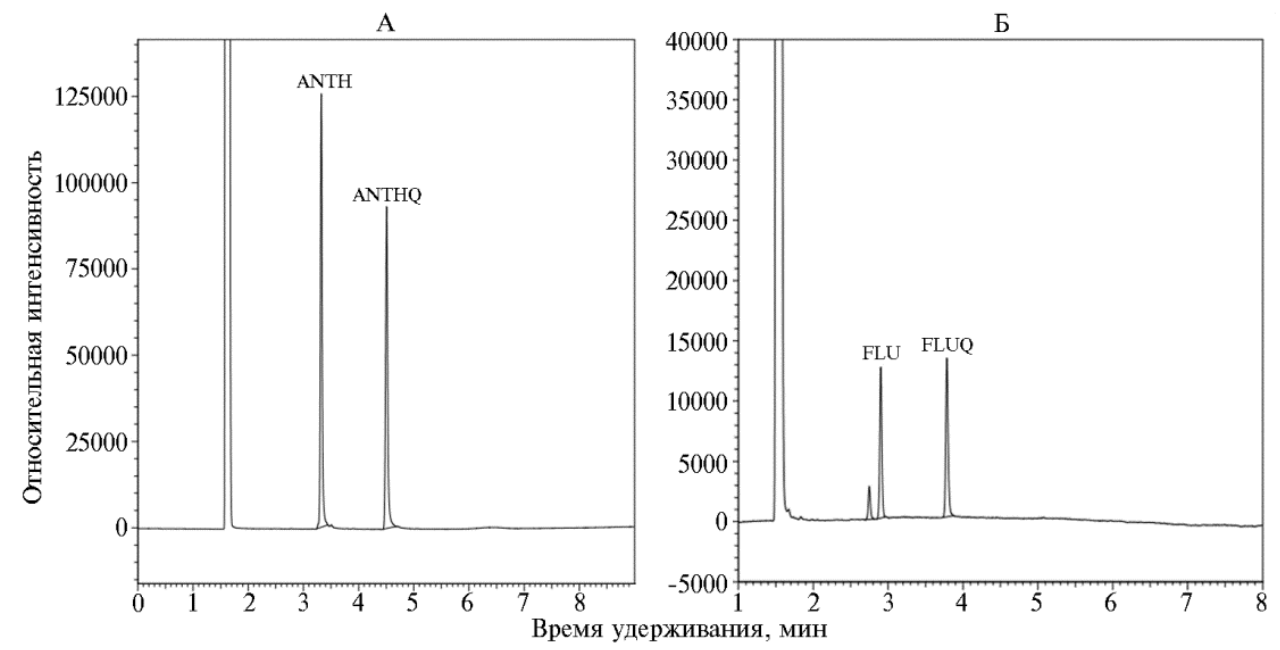

Рис. 2. Хроматограммы экстрактов культуральной жидкости Cladosporium herbarum MUT 3238 после деградации антрацена (А) и флуорена (Б): основные пики: ANTH - антрацен, ANTHQ 9,10-антрахинон, FLU - флуорен, FLUQ - 9-флуоренон. Хроматограф GC-2010 («Shimadzu Deutschland $\mathrm{GmbH»,} \mathrm{Германия)} \mathrm{с} \mathrm{пламенно-фотометрическим} \mathrm{детектором,} \mathrm{колонка} \mathrm{НP5}$ («Agilent Technologies Inc.», США).

При исследовании продуктов окисления трехциклических ПАУ антрацена и флуорена грибом $C$. herbarum с помощью ГЖХ был выявлен метаболит деградации антрацена $C$. herbarum - 9,10-антрахинон (рис. 2), который через 14 сут практически полностью разрушался с образованием 2,2'-дифеновой и фталевой кислот. Метаболит деградации флуорена этим грибом - 9-флуоренол выявлялся в следовых количествах, что может быть следствием быстрой утилизации исходного ПАУ. В качестве одного из конечных продуктов деградации флуорена была обнаружена фталевая кислота, которая, как известно, включается у грибов в основной обмен (41). 
При деградации флуорена грибом $F$. oxysporum наблюдалось образование и последующая утилизация 9-флуоренола, 9-флуоренона и 2-карбоксибензальдегида. Деградация ПАУ грибами C. herbarum и F. oxysporum происходила через образование и последующее разрушение хинонов, без накопления токсичных метаболитов. Следует отметить, что выявленные метаболиты были идентичны тем, которые мы обнаружили у базидиомицетов $(42,43)$, что позволяет предположить наличие подобных метаболических путей деградации ПАУ и у аскомицетов.

При изучении метаболизма ПАУ грибами L. aphanocladii и G. candidum таких однозначных результатов получить не удалось. В процессе деградации фенантрена L. aphanocladii были выявлены следовые количества фенантрен-9,10-хинона, которые исчезали с увеличением времени культивирования гриба. Обнаружение этого хинона и продукция штаммом Mnпероксидазы позволяют предположить у L. aphanocladii сходный с C. herbarum и $F$. oxysporum путь разрушения ПАУ. Хиноновые метаболиты при деградации ПАУ G. candidum выявлены не были.

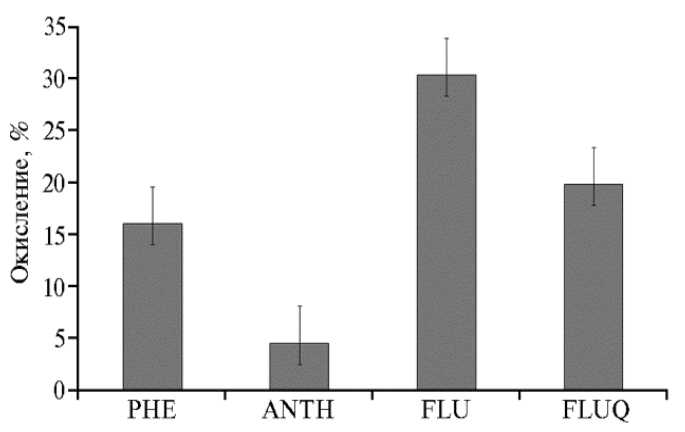

Рис. 3. Окисление полициклических ароматических углеводородов грубым ферментным препаратом пероксидазы Fusarium охуsporum IBPPM 543: PHE - фенантрен, ANTH - антрацен, FLU флуорен, FLUQ - 9-флуоренон (2-е сут; $n=3$, указаны стандартные отклонения).

Как упоминалось выше, три из четырех исследованных грибов продуцировали пероксидазу в ответ на присутствие в среде культивирования поллютантов. Известно, что лигнинолитические пероксидазы участвуют в деградации ПАУ, окисляя их с образованием соответствующих хинонов (21). Для выяснения роли обнаруженных Мn-пероксидаз аскомицетов в деградации ПАУ мы исследовали прямые реакции окисления трехциклических ПАУ ферментом из $F$. oxysporum. Нами был получен грубый препарат этого фермента, для чего грибной мицелий культивировали до достижения максимума продукции пероксидазы (20 Ед/мл), среду культивирования отделяли от мицелия фильтрованием, концентрировали в 50 раз ультрафильтрацией (фильтр Amicon PM-10, «Merck KGaA», Германия) и использовали как источник фермента. Обнаружено, что эта пероксидаза окисляла как нативные ПАУ флуорен и фенантрен, так и продукт окисления флуорена 9-флуоренон (рис. 3). Следовательно, именно внеклеточная грибная пероксидаза окисляла ПАУ, а также, по меньшей мере, фракцию полиядерных ароматических соединений нефти. Важно отметить, что в условиях нашего эксперимента грибы с различной экологической стратегией проявляли сходные свойства. Все штаммы обладали высокой нефтеокисляющей активностью. Потенциально энтомопатогенный L. aphanocladii по деструктивным свойствам и продукции Мn-пероксидазы был подобен сапротрофам $C$. herbarum и $F$. oxysporum. Существенно отличался от них условнопатогенный $G$. candidum, не проявивший значительной деструктивной активности в отношении ПАУ, что может быть следствием отсутствия у него внеклеточных пероксидаз, аналогичных лигнинолитическим, хотя в литературе этот вид упоминается как деструктор 2,4,6-тринитротолуола (14). У G. candidum окисление нефти и ПАУ, вероятно, обусловлено активностью 
других ферментов, например цитохром Р450-монооксигеназ (44).

Полученные нами результаты дают основания продолжить исследования, используя как классические биохимические методы выделения, очистки и всестороннего изучения ферментов и способов деградации поллютантов, так и современные молекулярно-биологические подходы, позволяющие установить наличие и экспрессию соответствующих генов.

Таким образом, представители двух широко распространенных в природе видов аскомицетов Cladosporium herbarum u Fusarium oxysporum, a также штамм менее известного и мало изученного вида Lecanicillium aphanocladii обладают высоким деструктивным потенциалом в отношении нефти и полициклических ароматических углеводородов (ПАУ), что предполагает участие этих микромицетов в процессах самоочищения природных экосистем от поллютантов. Выявление лигнинолитических ферментов и соответствующих продуктов деградации ПАУ свидетельствует в пользу экологически целесообразного пути утилизации ПАУ (с образованием хинонов), что снижает негативные последствия, связанные с возможным образованием токсичных метаболитов. У штамма Geotrichum candidum лигнинолитические ферменты не обнаружены и окисление нефти и ПАУ могут выполнять другие ферменты, например цитохром Р450-монооксигеназы. Кроме того, велика вероятность наличия у этого штамма так называемой обесцвечивающей пероксидазы, имеющей узкий спектр субстратной специфичности и катализирующей обесцвечивание антрахиноновых красителей. Способность исследованных штаммов разрушать поллютанты делает их перспективными для практического использования в биоремедиационных и других биотехнологических процессах.

Aвторы благодарят профессора G.C. Varese (Department of Life Sciences and Systems Biology, University of Turin, г. Турин, Италия) за любезно предоставленные ею штаммы грибов.

ФГБУН Институт биохимии и физиологии растений и микроорганизмов РАН,

410049 Россия, г. Саратов, просп. Энтузиастов, 13,

e-mail: turkovskaya_o@ibppm.ru $₫$, dubrovskaya_e@ibppm.ru,

grinev_v@ibppm.ru, sveta.balandinp@mail.ru,pozdnyakova_n@ibppm.ru
Поступила в редакцию 15 августа 2018 года

Sel’skokhozyaistvennaya biologiya [Agricultural Biology], 2019, V. 54, № 1, pp. 65-75

\section{DEGRADATIVE ACTIVITY AND PRODUCTION \\ OF THE EXTRACELLULAR PEROXIDASES BY MICROMYCETES WITH DIFFERENT ECOLOGICAL STRATEGY}

\section{O.V. Turkovskaya, E.V. Dubrovskaya, V.S. Grinev, S.A. Balandina, N.N. Pozdnyakova}

Institute of Biochemistry and Physiology of Plants and Microorganisms RAS, 13, prosp. Entuziastov, Saratov, 410049 Russia, e-mail turkovskaya_o@ibppm.ru( $₫$ corresponding author), dubrovskaya_e@ibppm.ru, grinev_v@ibppm.ru, sveta.balandinp@mail.ru, pozdnyakova_n@ibppm.ru

ORCID:

Turkovskaya O.V. orcid.org/0000-0003-4501-4046

Dubrovskaya E.V. orcid.org/0000-0001-7944-6483

Balandina S.A. orcid.org/0000-0002-1971-0016

Grinev V.S. orcid.org/0000-0002-0627-6804

Pozdnyakova N.N. orcid.org/0000-0003-2097-3371

The authors declare no conflict of interests

Acknowledgements:

We are grateful to Prof. G.C. Varese (Department of Life Sciences and Systems Biology, University of Turin) for kindly providing us with fungal strains.

Supported financially by Russian Science Foundation (grant No. 16-14-00081, the PAH degradation part), and by

Russian Foundation for Basic Research (grant No. 18-29-05062, the oil degradation part)

Received August 15, 2018 doi: 10.15389/agrobiology.2019.1.65eng

\section{Abstract}

Environmental pollution by natural and man-made pollutants remains a serious problem. Agricultural areas are contaminated by major and hazardous pollutants such as oil, which comes 
from local oil-producing and oil-refining facilities, and polycyclic aromatic hydrocarbons (PAHs), which result from natural fires and from human activity associated with the use of flammable organic raw materials. This presents the hazard of accumulation of toxic substances in food and fodder plants. Natural ecosystems have powerful detoxifying potential, which is ensured by the degradative activity of microorganisms, including ascomycetes - one of the largest groups in the fungal kingdom. Here we examined the degradation of oil and PAHs by micromycetes with different ecological strategies and detected ligninolytic enzymes implicated in the oxidation of the pollutants. We used four ascomycete strains with different taxonomic affiliations and ecological strategies. These were Fusarium oxysporum IBPPM543, Lecanicillium aphanocladii IBPPM542, Cladosporium herbarum MUT3238, and Geotrichum candidum MUT4803. The fungi were grown in liquid media with different compositions that received additions of the pollutants used: oil, PAHs, and anthraquinonetype dyes. After 14 days of fungal growth, the elimination of the pollutants and the content of their main degradation products were examined by GC. Ligninolytic enzyme activity was estimated spectrophotometrically by the oxidation rate of the corresponding test substrates. All treatments in the experiments and analyses had no less than three replications, and each experiment was repeated no less than three times. Data were processed with Microsoft Excel 2003 software. All fungi oxidized oil; the utilization was from 46 to $82 \%$ of the initial concentration of $5 \mathrm{~g} / \mathrm{l}$ within 14 days. C. herbarum MUT 3238 metabolized all PAHs included in the study (anthracene, phenanthrene, and fluorene) almost completely (initial concentration, $0.05 \mathrm{~g} / \mathrm{l}$ ). L. aphanocladii IBPPM 542 degraded anthracene, phenanthrene, and fluorene by 40,63 , and $81 \%$, respectively. F. oxysporum IBPPM 543 utilized phenanthrene and fluorene only by 20 and $40 \%$, respectively. PAH degradation by G. candidum MUT4803 was not greater than $18 \%$. Anthracene was not degraded by $F$. oxysporum IBPPM 543 and $G$. candidum MUT4803. The degradation of the pollutants was accompanied by the production of extracellular peroxidases by all fungi except $G$. candidum. The activities of these peroxidases were largely stimulated by $\mathrm{Mn}^{2+}$; this property makes them similar to the Mn-peroxidases of basidiomycetes. This is the first report on the production of extracellular peroxidases by $C$. herbarum and L. aphanocladii. Neither of the fungi produced lignin peroxidase or laccase. Identification of the PAH oxidation products allowed us to suggest a pathway for PAH degradation by the tested fungi with an extracellular Mn-peroxidase. The degradation proceeds through the formation of quinones and carboxylic acids (phthalic and 2,2'-diphenic), which indicates that the PAHs are utilized almost completely and that no toxic metabolites accumulate. The obtained results indicate that two widely distributed ascomycete species, $C$. herbarum and $F$. oxysporum, and a strain of the lesser-known and poorly studied species L. aphanocladii, have degradative potential toward oil and PAHs, which presupposes their involvement in the self-cleaning of the environment from these pollutants. The detection of ligninolytic enzymes (Mn-peroxidases) and of the corresponding products of PAH degradation speaks in favor of an ecologically appropriate pathway for the utilization of PAHs, which reduces the negative consequences associated with the possible formation of toxic metabolites. In the G. candidum strain, the oxidation of oil and PAHs is possibly due to the activity of other enzymes, for example cytochrome P450 monooxygenase, because no ligninolytic enzymes have been found. In addition, it is highly possible that this strain has a "dye peroxidase", which requires a narrow range of substrates and catalyzes the degradation of anthraquinone dyes, as was also shown by us. The ability of all fungal strains to degrade pollutants makes them promising candidates for practical use in bioremediation and other biotechnologies.

Keywords: ascomycetes, Fusarium oxysporum, Lecanicillium aphanocladii, Cladosporium herbarum, biodegradation, polycyclic aromatic hydrocarbons, oil, ligninolytic enzymes, peroxidases.

\section{REFEREN C ES}

1. Vasil'ev A.V., Bykov D.E., Pimenov A.A. Izvestiya Samarskogo nauchnogo tsentra RAN, 2015, 17(4): 269-272 (in Russ.).

2. Gorobtsova O.N., Nazarenko O.G., Minkina T.M., Borisenko N.I., YAroshchuk A.V. Izvestiya vuzov. Severo-Kavkazskii region. Estestvennye nauki, 2005, 1: 73-78 (in Russ.).

3. Gagkaeva T.Yu., Shamshev I.V., Gavrilova O.P., Selitskaya O.G. Biological relationships between Fusarium fungi and insects (review). Sel'skokhozyaistvennaya Biologiya [Agricultural Biolo$g y$ ], 2014, 3: 13-23 (doi: 10.15389/agrobiology.2014.3.13eng) (in Russ.).

4. Dinolfo M.I., Castañares E., Stenglei S.A. Fusarium-plant interaction: state of the art - a review. Plant Protect. Sci., 2017, 53: 61-70 (doi: 10.17221/182/2015-PPS).

5. Gordon T.R., Okamoto D., Jacobson D.J. Colonization of muskmelon and nonsusceptible crops by Fusarium oxysporum f. sp. melonis and other species of Fusarium. Phytopathology, 1989, 79(10): 1095-1100 (doi: 10.1094/Phyto-79-1095).

6. Lemanceau P., Bakker P.A.H.M., DeKogel W.J., Alabouvette C., Schippers B. Antagonistic effect of nonpathogenic Fusarium oxysporum Fo47 and pseudobactin 358 upon pathogen Fusarium oxysporum f. sp. dianthi. Appl. Environ. Microbiol., 1993, 59(1): 74-82. 
7. Jacques R.J., Okeke B.C., Bento F.M., Teixeira A.S., Peralba M.C., Camargo F.A. Microbial consortium bio ugmentation of a polycyclic aromatic hydrocarbons contaminated soil. Bioresource Technol., 2008, 99(7): 2637-2643 (doi: 10.1016/j.biortech.2007.04.047).

8. Thion C., Cébron A., Beguiristain T., Leyval C. Inoculation of PAH-degrading strains of Fusarium solani and Arthrobacter oxydans in rhizospheric sand and soil microcosms: microbial interactions and PAH dissipation. Biodegradation, 2013, 24(4): 569-581 (doi: 10.1007/s10532-0139628-3).

9. Krivobok S., Miriouchkine E., Seigle-Murandi F., Benoit-Guyod J.-L. Biodegradation of anthracene by soil fungi. Chemosphere, 1998, 37(4): 523-530 (doi: 10.1016/S0045-6535(98)00067-8).

10. Potin O., Veignie E., Rafin C. Biodegradation of polycyclic aromatic hydrocarbons (PAHs) by Cladosporium sphaerospermum isolated from an aged PAH contaminated soil. FEMS Microbiol. Ecol., 2004, 51(1): 71-78 (doi: 10.1016/j.femsec.2004.07.013).

11. Boutrou R., Guéguen T.M. Interests in Geotrichum candidum for cheese technology. Int. J. Food Microbiol., 2005, 102(1): 1-20 (doi: 10.1016/j.ijfoodmicro.2004.12.028).

12. Kim S.J., Ishikawa K., Hirai M., Shoda M. Characteristics of a newly isolated fungus, Geotrichum candidum Des 1, which decolorizes various dyes. Journal of Fermentation and Bioengineering, 1995, 79(6): 601-607 (doi: 10.1016/0922-338X(95)94755-G).

13. Kim S.J., Shoda M. Purification and characterization of a novel peroxidase from Geotrichum candidum Dec 1 involved in decolorization of dyes. Appl. Environ. Microb., 1999, 65(3): 1029-1035.

14. Ziganshin A.M., Gerlach R., Naumenko E.A., Naumova R.P. Aerobic degradation of 2,4,6trinitrotoluene by the yeast strain Geotrichum candidum AN-Z4. Microbiology, 2010, 79(2): 178183 (doi: 10.1134/S0026261710020086).

15. Jakovljević V.D., Vrvić M.M. Potential of pure and mixed cultures of Cladosporium cladosporioides and Geotrichum candidum for application in bioremediation and detergent industry. Saudi $J$. Biol. Sci., 2018, 25(3): 529-536 (doi: 10.1016/j.sjbs.2016.01.020).

16. Zare R., Gams W. A revision of Verticillium section Prostrata. IV. The genera Lecanicillium and Simplicillium gen. nov. Nova Hedwigia, 2001, 73(1/2): 1-50.

17. Manfrino R.G., González A., Barneche J., Tornesello Galván J., Hywell-Jones N., LypezLastra C.C. Contribution to the knowledge of pathogenic fungi of spiders in Argentina. Southernmost record in the world. Rev. Argent. Microbiol., 2017, 49(2): 197-200 (doi: 10.1016/j.ram.2016.10.007).

18. El-Debaiky S.A. New record of Lecanicillium aphanocladii family: Cordycipitaceae from Egypt. J. Bacteriol. Mycol. Open Access, 2017, 5(7): 00161 (doi: 10.15406/jbmoa.2017.05.00161).

19. Pinto A., Serrano C., Pires T., Mestrinho E., Dias L., Teixeira D., Caldeira A. Degradation of terbuthylazine, difenoconazole and pendimethalin pesticides by selected fungi cultures. Sci. Total Environ., 2012, 435-436(1): 402-410 (doi: 10.1016/j.scitotenv.2012.07.027).

20. Vroumsia T., Steiman R., Seigle-Murandi F., Benoit-Guyod J.-L. Effects of culture parameters on the degradation of 2,4-dichlorophenoxyacetic acid (2,4-D) and 2,4-dichlorophenol (2,4-DCP) by selected fungi. Chemosphere, 1999, 39(9): 1397-1405 (doi: 10.1016/S00456535(99)00042-9).

21. Kadri T., Rouissi T., Brar S.K., Cledon M., Sarma S., Verma M. Biodegradation of polycyclic aromatic hydrocarbons (PAHs) by fungal enzymes: A review. J. Environ. Sci., 2017, 51(1): 52-74 (doi: 10.1016/j.jes.2016.08.023).

22. Ghosal D., Ghosh S., Dutta T.K., Ahn Y. Current state of knowledge in microbial degradation of polycyclic aromatic hydrocarbons (PAHs): A Review. Front. Microbiol., 2016, 7: 1369 (doi: 10.3389/fmicb.2016.01369).

23. Bezalel L., Hadar Y., Cerniglia C. Enzymatic mechanisms involved in phenanthrene degradation by the white rot fungus Pleurotus ostreatus. Appl. Environ. Microbiol., 1997, 63(7): 2495-2501.

24. Kirk T., Croan S., Tien M., Murtagh K., Farrell R. Production of multiple ligninases by Phanerochaete chrysosporium effect of selected growth condition and use mutant strain. Enzyme Microb. Tech., 1986, 8(1): 27-32.

25. Pozdnyakova N.N., Jarosz-Wilkolazka A., Polak J., Graz M., Turkovskaya O.V. Decolourisation of anthraquinone-and anthracene-type dyes by versatile peroxidases from Bjerkandera fumosa and Pleurotus ostreatus D1. Biocatal. Biotransform., 2015, 33(2): 69-80 (doi: 10.3109/10242422.2015.1060227).

26. Metody analiza organicheskogo veshchestva porod, nefti $i$ gaza /Pod redaktsiei A.V. Ryl'kova [Methods for analyzing rock organic matter, oil and gas. A.V. Ryl'kov (ed.)]. Tyumen', 1977 (in Russ.).

27. Niku-Paavola M.L., Karhunen E., Salola P., Raunio V. Ligninolytic enzymes of the white rot fungus Phlebia radiata. Biochem. J., 1988, 254(3): 877-884 (doi: 10.1042/bj2540877).

28. Heinfling A., Martinez M., Martinez A., Bergbauer M., Szewzyk U. Purification and characterization of peroxidases from dye-decolorizing fungus Bjerkandera adusta. FEMS Microbiol. Lett., 1998, 165(1): 43-50 (doi: 10.1016/S0014-5793(98)00512-2).

29. Tien M., Kirk K. Lignin-degrading enzyme from Phanerochaete chrysosporium: purification, characterization, and catalytic properties of a unique $\mathrm{H}_{2} \mathrm{O}_{2}$-requiring oxygenase. PNAS USA, 1984, 81(8): 2280-2284 (doi: 10.1073/pnas.81.8.2280). 
30. Sardrood B.P., Goltapeh E.M., Varma A. An introduction to bioremediation. In: Fungi as Bioremediators. Soil Biology, V. 32. E. Goltapeh, Y. Danesh, A. Varma (eds.). Springer, Berlin, Heidelberg, 2013 (doi: 10.1007/978-3-642-33811-3_1).

31. Mohsenzadeh F., Nasseri S., Mesdaghinia A., Nabizadeh R., Zafari D., Khodakaramian G., Chehregani A. Phytoremediation of petroleum-polluted soils: Application of Polygonum aviculare and its root-associated (penetrated) fungal strains for bioremediation of petroleum-polluted soils. Ecotox. Environ. Safe., 2010, 73(4): 613-619 (doi: 10.1016/j.ecoenv.2009.08.020).

32. Varjani S.J. Microbial degradation of petroleum hydrocarbons. Bioresource Technol., 2017, 223(1): 277-286 (doi: 10.1016/j.biortech.2016.10.037).

33. Balaji V., Arulazhagan P., Ebenezer P. Enzymatic bioremediation of polyaromatic hydrocarbons by fungal consortia enriched from petroleum contaminated soil and oil seeds. J. Environ. Biol., 2014, 35: 521-529.

34. Wong D.W.S. Structure and action mechanism of ligninolytic enzymes. Appl. Biochem. Biotech., 2009, 157(2): 174-209 (doi: 10.1007/s12010-008-8279-z).

35. Obruca S., Marova I., Matouskova P., Haronikova A., Lichnova A. Production of lignocellulosedegrading enzymes employing Fusarium solani F-552. Folia Microbiol., 2012, 57(3): 221-227 (doi: $10.1007 / \mathrm{s} 12223-012-0098-5)$.

36. Kwiatos N., Ryngajłł M., Bielecki S. Diversity of laccase-coding genes in Fusarium oxysporum genomes. Front. Microbiol., 2015, 6: 33 (doi: 10.3389/fmicb.2015.00933).

37. Wua Y.-R., Luo Z.-H., Vrijmoed L.L.P Biodegradation of anthracene and benz[a]anthracene by two Fusarium solani strains isolated from mangrove sediments. Bioresource Technol., 2010, 101(24): 9666-9672 (doi: 10.1016/j.biortech.2010.07.049).

38. Sampedro I., D'Annibale A., Ocampo J.A., Stazi S.R., García-Romera I. Solid-state cultures of Fusarium oxysporum transform aromatic components of olive-mill dry residue and reduce its phytotoxicity. Bioresource Technol., 2007, 98(18): 3547-3554 (doi: 10.1016/j.biortech.2006.11.015).

39. Asses N., Ayed L., Bouallagui H., Sayadi S., Hamdi M. Biodegradation of different molecularmass polyphenols derived from olive mill wastewaters by Geotrichum candidum. International Biodeterioration \& Biodegradation, 2009, 63(4): 407-413 (doi: 10.1016/j.ibiod.2008.11.005).

40. Ayed L., Assas N., Sayadi S., Hamdi M. Involvement of lignin peroxidase in the decolourization of black olive mill wastewaters by Geotrichum candidum. Lett. Appl. Microbiol., 2005, 40(1): 7-11 (doi: 10.1111/j.1472-765X.2004.01626.x).

41. Hammel K., Green B., Gai W. Ring fission of anthracene by eukaryote. PNAS USA, 1991, 88(23): 10605-10608 (doi: 10.1073/pnas.88.23.10605).

42. Pozdnyakova N.N., Chernyshova M.P., Grinev V.S., Landesman E.O., Koroleva O.V., Turkovskaya O.V. Prikladnaya biokhimiya $i$ mikrobiologiya, 2016, 52(6): 590-598 (doi: 10.7868/S0555109916060131) (in Russ.).

43. Pozdnyakova N., Dubrovskaya E., Chernyshova M., Makarov O., Golubev S., Balandina S., Turkovskaya $\mathrm{O}$. The degradation of three-ringed polycyclic aromatic hydrocarbons by woodinhabiting fungus Pleurotus ostreatus and soil-inhabiting fungus Agaricus bisporus. Fungal Biology, 2018, 122(5): 363-372 (doi: 10.1016/j.funbio.2018.02.007).

44. Ning D., Wang H., Ding C., Lu H. Novel evidence of cytochrome P450-catalyzed oxidation of phenanthrene in Phanerochaete chrysosporium under ligninolytic conditions. Biodegradation, 2010, 21(6): 889-901 (doi: 10.1007/s10532-010-9349-9). 